Umbrella Review

\title{
Lower Limb Exercise-Based Injury Prevention Programs Are Effective in Improving Sprint Speed, Jumping, Agility and Balance: an Umbrella Review
}

\author{
Loïc Bel, PT, Bsc Msc Cand. ${ }^{1}$ ', Nicolas Mathieu, PT, BSc, MSc ${ }^{1}$, Vincent Ducrest, PT, BSc ${ }^{1}, \mathrm{Mario}$ Bizzini, PT, PhD ${ }^{2}$ \\ 1 Physiotherapy, HES-SO Valais, University of Applied Sciences Western Switzerland, ${ }^{2}$ Research, Schulthess Clinic Human Performance Lab \\ Keywords: systematic review, performance, prevention programs, lower limb injury, exercise \\ https://doi.org/10.26603/001c.29860
}

International Journal of Sports Physical Therapy

Vol. 16, Issue 6, 2021

\section{Background}

Exercise-based injury prevention programs for athletes have demonstrated consistent results in reducing the risk of lower limb injuries. Compliance is essential for program effectiveness and may be facilitated when these programs demonstrate positive effects on athletic performance.

\section{Hypothesis/Purpose}

To summarize the findings of current systematic reviews on the effectiveness of lower limb injury prevention programs with multiple neuromuscular components on sports performance and quantify these effects. The authors hypothesized that injury prevention programs can improve certain sports performance criteria.

\section{Study Design}

Umbrella systematic review

\section{Methods}

Systematic reviews published in French, German, or English between January 1990 and January 2020 were identified in five databases. Only articles that investigated multicomponent lower limb injury prevention programs and their effects on the performance criteria of strength, balance, agility, jumping or speed by both amateur and professional athletes of all ages and sex were included. The methodological quality of the included systematic reviews was assessed by two reviewers independently using the Assessing the Methodological Quality of Systematic Reviews measurement tool.

\section{Results}

Five systematic reviews met the inclusion criteria. Overall, beneficial effects of multicomponent exercise-based injury prevention programs were observed for balance, agility, jumping and speed. While the effects on strength were more variable, there was a positive trend in favor of injury prevention programs.

\section{Conclusion}

Injury prevention programs with multiple neuromuscular exercise components demonstrate overall beneficial effects on the performance criteria of balance, agility, jumping or speed. These beneficial effects may be used to promote the implementation of such programs.

\section{Level of Evidence}




\section{INTRODUCTION}

Physical activity is an important component of good health for all individuals and recommended for improving cardiorespiratory and muscular capacity, bone health and reducing the risk of depression and non-communicable diseases. $^{1}$ However, participation in recreational or competitive sports is not without an increased risk of acute injury or overload. ${ }^{2,3}$ Many interventions have been developed to reduce the risk of sports-related injuries, especially at the lower limb. In particular, prevention programs composed of several neuromuscular training components such as muscle strengthening, balance and agility training have demonstrated preventive effects for lower limb injuries. ${ }^{4-7}$ While these programs have around 39\% efficacy in reducing the risk of lower extremity injury and even higher efficacies of $54 \%$ and $50 \%$ for acute knee injuries and ankle sprains respectively, ${ }^{8}$ the effects may vary.

Compliance with injury prevention programs plays a key role in achieving the greatest possible preventive effect. ${ }^{9-12}$ To increase compliance, it has been suggested that the coach is the most important person to promote the process of implementing an injury prevention program, ${ }^{13,14}$ and regular practice of these programs is also required to achieve the desired outcome. $5,15,16$ Yet a coach can more easily be persuaded when a better understanding of the motivations and facilitators behind program implementation is attained. ${ }^{15,17}$ From the trainer's perspective, one of the key factors in sport is performance; the implementation of prevention programs could be facilitated if these protocols were to demonstrate positive effects on performance. ${ }^{11,18-21}$ In fact, performance is identified as the primary goal of elite sport by coaches as well as athletes and sport physiotherapists. ${ }^{22}$ Athletic performance is defined as the ability to respond effectively to the specific physical demands of the sport being played. ${ }^{23}$ Several performance factors include maximum muscle strength and muscle power, agility, speed, flexibility, balance and stability. ${ }^{23}$ Furthermore, injury prevention is defined as an accessory goal in achieving athletic performance. ${ }^{24}$

The effects of injury prevention programs on performance must be clearly understood to facilitate the primary implementation of these programs by coaches. Therefore, our study objectives were to summarize the findings of current systematic reviews on the effectiveness of lower limb injury prevention programs with multiple neuromuscular components on sports performance and to quantify their effects. We hypothesized that injury prevention programs can improve certain performance criteria.

\section{METHODS}

This umbrella review was carried out according to the model of Aromataris et al. ${ }^{25}$ Details of the review protocol are registered on PROSPERO and can be accessed at https://www.crd.york.ac.uk/prospero/display_record.php?ID=CRD42020162334.

\section{SEARCH METHODOLOGY}

For this umbrella review, two authors compiled all evidence from pertinent systematic reviews found within the following databases: PubMed, CINAHL, Ovid, Cochrane Database of Systematic Reviews, and PEDro. The search strategy was guided using the Population Intervention Comparison Outcome Study Design (PICOS) approach and selected terms were combined in a Boolean search. Key terms used were "sportsman", "sportswoman”, "injury prevention program” and "performance". More details about the search strategy used and the results for every database can be found in Appendix 1 .

All systematic reviews had to be written in French, German or English and published between January 1, 1990 and January 31, 2020. Thereafter, a sports injury prevention expert/co-author identified any further references relevant to the topic, which had not been identified by the initial search strategy and to ensure comprehensive coverage of the literature.

All identified references were imported into the Covidence systematic review software (www.covidence.org) (Veritas Health Innovation, Melbourne, Australia) to identify and remove duplicates. Two authors then independently screened all article titles and abstracts to select relevant reviews eligible for full-text reading. The inclusion criteria were defined as follows:

Population: athletes of all ages and sex who participate in any sport (e.g. soccer, basketball, volleyball, ice hockey)

Intervention: all types of multicomponent exercise intervention (e.g. strength, balance, plyometrics...) used with the goal to prevent injuries of the lower limb

Comparison: usual training and/or usual warm-up procedures

Outcomes: performance criteria defined as: (1) strength, (2) balance, (3) agility, (4) jumping ability, or (5) speed.

Exclusion criteria were defined as not meeting one or more of the defined inclusion criteria. If there was any doubt about the eligibility of a screened reference, consensus was reached primarily by discussion and a third author was only consulted when the reference's eligibility could not be established.

\section{METHODOLOGICAL QUALITY ASSESSMENT}

The Assessing the Methodological Quality of Systematic Reviews (AMSTAR) tool was used to classify the reviews according to their methodological quality. Eleven items are assessed using the options of "yes", "no", "not applicable" and "cannot answer", where single points on the AMSTAR scale can only be accumulated for each "yes" answer. The AMSTAR ranking is based on three categories indicating low quality reviews with scores of 0 to 3 points and reviews of moderate (4 to 7 points) and high quality (8 to 11 points). ${ }^{26,27}$ Two authors independently assessed the methodological quality of the included systematic reviews according to AMSTAR and only those of moderate or high quality were included, as summarized in Table 1. Any AMSTAR rating conflicts were resolved by discussion with a third author until consensus was reached. 


\section{DATA EXTRACTION AND ANALYSIS}

The data extraction process was carried out independently by two authors. Information on the author, publication year, sample size, intervention and study outcomes was collated and managed in Microsoft Excel 2020. For any conflicting data, a third author was consulted until consensus was reached.

The outcomes analyzed for this umbrella review included the following performance measures of: strength (quadriceps and hamstring isokinetic strength and hamstring/ quadriceps ratios), balance (ability to maintain one's center of gravity within their base of support), agility (ability to change direction), jumping abilities (horizontal and vertical jumping as well as reactive jumping [e.g. drop jumping]) and sprint speed (in a straight line). Further data on the number of study participants, sex of the study population, and type of sport participated in were also exported. If a meta-analysis was conducted within the systematic review, the results of the studies were reported using the standardized mean difference (SMD), 95\% confidence interval (95\% $\mathrm{CI})$ and $\mathrm{I}^{2}$ test. When the SMD was not reported, other measures including either the mean difference (MD) or percentage of change from baseline were noted as available. When a meta-analysis was not performed, a narrative synthesis of the study results-describing the findings of the included studies based on outcomes and intervention types executed-was provided.

For all meta-analyses, effect sizes were categorized according to Cohen ${ }^{27}$ as follows: values of 0 to 0.19 indicate a negligible effect, 0.20 to 0.49 represents a small effect, 0.50 to 0.79 a moderate effect, and greater than 0.80 a large effect.

Based on the umbrella review guidelines, ${ }^{25}$ a "traffic lights" system was used to summarize the effectiveness of prevention programs on the various performance criteria selected. A red color indicates that the intervention may be detrimental or less effective than the comparator (i.e. normal training program). An orange color was set for reviewed studies showing no difference between the comparison and intervention, and green denoted any beneficial effect of the intervention.

\section{RESULTS}

A total of 4,816 studies were initially identified with an additional reference discovered by the injury prevention expert (Figure 1).

After the removal of all duplicates, 4,012 abstracts and article titles were screened, and 4,004 references were excluded after reading the titles and abstracts. The full text of the remaining eight references was read and two studies were excluded because they did not meet the inclusion criteria. The methodological quality of the remaining six studies was assessed, which resulted in the exclusion of one study $^{28}$ due to its low methodological quality (AMSTAR score $\leqslant 3$ ). The overall methodological quality of the final reference selection-comprising five systematic reviews that assessed the quality of 61 primary studies-as summarized in Table 1.

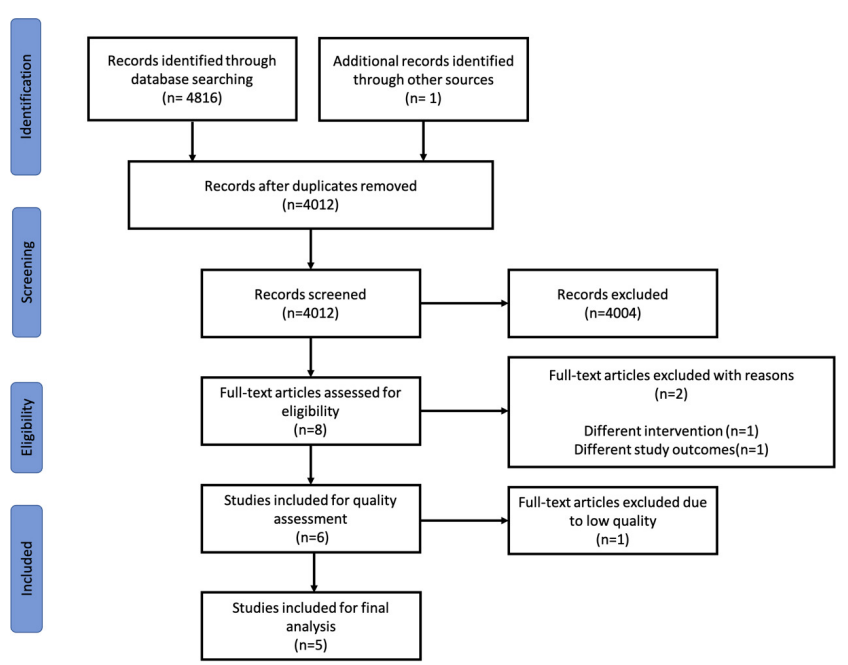

Figure 1. PRISMA Diagram

\section{INJURY PREVENTION PROGRAMS}

A comprehensive summary of the review findings outlining the effects of injury prevention exercises on the selected performance criteria is detailed in Appendix 2.

\section{EFFECTS ON STRENGTH}

Of the five systematic reviews, four evaluated the effect of neuromuscular exercise programs aimed at reducing the risk of injury on strength. ${ }^{29,31-33}$ For hamstring strength, small to moderate improvements were reported for isokinetic speeds of $60 \%$ s (SMD: 0.56 ) and $240 \%$ s (SMD: 0.31). ${ }^{29}$ Another review found an improvement in hamstring strength when interventions included eccentric hamstring strengthening exercises. ${ }^{32}$ Yet only small to negligible effects were observed in favor of improving quadriceps strength at isokinetic velocities of $60 \%$ s (SMD: 0.49 ) and $240 \%$ s (SMD: 0.19 ). ${ }^{29}$ The group of ter Stege reviewed studies focused on overall strength of the lower limb and found an improvement in the strength of the entire lower limb. ${ }^{33}$ For hamstring-quadriceps ratios, a small positive effect was noted only at an isokinetic velocity of $60 \%$ s (SMD: 0.40 ) with negligible effects at $240 \%$ s (SMD: 0.13). ${ }^{29}$ The effects of interventions on hamstring-quadriceps force ratios were variable ${ }^{32,33}$ but an $11.3 \%$ improvement in strength in favor of prevention programs was reported. 31

\section{EFFECTS ON BALANCE}

Four reviews evaluated the effects of prevention programs on balance. A small positive effect (SMD: 0.29) was noted for static balance. ${ }^{29}$ For dynamic balance, the effects were also positive but variable: one review found a small effect (SMD: 0.31), ${ }^{29}$ another found a large effect size (MD: $2.68),{ }^{30}$ and a third review reported the overall effectiveness of interventions on balance with an average improvement of $5.2 \%$ in scores between the baseline and post-intervention time points. ${ }^{31}$ The fourth review highlighted the variability in outcomes, but noted that dynamic balance can be improved in both groups; there was no improvement in dy- 
Table 1. Methodological quality assessment of systematic reviews using AMSTAR.

\begin{tabular}{|c|c|c|c|c|c|c|}
\hline \multirow[b]{2}{*}{ AMSTAR items } & \multicolumn{5}{|c|}{ Systematic review } & \multirow[b]{2}{*}{$\begin{array}{c}\text { ter } \\
\text { Stege } \\
\text { et } \\
\mathrm{al}^{33}\end{array}$} \\
\hline & $\begin{array}{l}\text { Barengo } \\
\text { et } \mathrm{al}^{28}\end{array}$ & $\begin{array}{c}\text { Faude } \\
\text { et } \\
\text { al }^{29}\end{array}$ & $\begin{array}{c}\text { Gomes } \\
\text { Neto et } \\
\text { al }^{30}\end{array}$ & $\begin{array}{l}\text { Hanlon } \\
\text { et } \mathrm{al}^{31}\end{array}$ & $\begin{array}{l}\text { Monajati } \\
\text { et } \mathrm{al}^{32}\end{array}$ & \\
\hline Was an "a priori" design provided? & No & Yes & No & No & Yes & No \\
\hline $\begin{array}{l}\text { Was there duplicate selection and data } \\
\text { extraction? }\end{array}$ & Yes & Yes & Yes & Yes & Yes & Yes \\
\hline $\begin{array}{l}\text { Was a comprehensive literature search } \\
\text { performed? }\end{array}$ & Yes & Yes & Yes & Yes & Yes & Yes \\
\hline $\begin{array}{l}\text { Was the status of publication used as an } \\
\text { inclusion criterion? }\end{array}$ & No & Yes & Yes & Yes & CA & CA \\
\hline $\begin{array}{l}\text { Was a list of included/excluded studies } \\
\text { provided? }\end{array}$ & No & No & No & No & Yes & No \\
\hline $\begin{array}{l}\text { Were the profiles of the included studies } \\
\text { provided? }\end{array}$ & Yes & Yes & Yes & Yes & Yes & Yes \\
\hline $\begin{array}{l}\text { Was the methodological quality of the included } \\
\text { studies evaluated and documented? }\end{array}$ & No & Yes & Yes & Yes & Yes & Yes \\
\hline $\begin{array}{l}\text { Was the specific quality of the included studies } \\
\text { used appropriately in formulating conclusions? }\end{array}$ & No & Yes & Yes & No & Yes & Yes \\
\hline $\begin{array}{l}\text { Were the methods used to combine the findings } \\
\text { of studies appropriate? }\end{array}$ & N/A & Yes & Yes & Yes & N/A & N/A \\
\hline Was the publication bias evaluated? & No & Yes & No & Yes & No & No \\
\hline Were the conflicts of interest stated? & No & No & No & No & No & No \\
\hline Total AMSTAR score & $3 / 11$ & 9/11 & $7 / 11$ & $7 / 11$ & $7 / 11$ & $5 / 11$ \\
\hline
\end{tabular}

$N / A=$ not applicable, $C A=$ can't answer

namic balance in the pediatric group. ${ }^{33}$ For dynamic stability, moderate effects were observed (SMD: 0.72). ${ }^{29}$

\section{EFFECTS ON AGILITY, JUMPING AND SPEED}

Two reviews identified large (SMD: 0.88) as well as weak effects (SMD: 0.25 ) in favor of prevention programs on agility. ${ }^{29,30}$

Two reviews identified the effects of prevention programs on vertical jumping and demonstrated small (SMD: $0.31^{29}$ and $0.24^{30}$ ), yet overall effectiveness of interventions on this outcome. For reactive jumping, weak effects (SMD: 0.29 ) were seen and for the horizontal jumping, there were negligible effects in favor of implementing prevention programs (SMD: 0.04). ${ }^{29}$ Three reviews evaluated the effects of prevention programs on speed. There were moderate effects of prevention programs (SMD: 0.66) on sprint speed, ${ }^{29}$ although another review only found a weak effect (SMD: 0.36). ${ }^{30}$ As a result of injury prevention programs in youth athletes, Hanlon et al only found a $2.2 \%$ improvement in speed, ${ }^{31}$ whereas an earlier review also focused on youth sports observed a large effect in favor of such programs (SMD: 0.92). ${ }^{29}$

\section{DISCUSSION}

The results of this umbrella review showed that there were five systematic reviews of moderate to high quality that examined the effects of lower extremity injury prevention programs on the performance outcomes analyzed. While the results for strength were quite variable, there was a trend indicating small to moderate improvements in this performance parameter as a result of prevention exercises. For the performance criteria of balance, agility, jumping and speed, the reviews demonstrated the clinical efficacy of prevention programs over control interventions. It is important to note that we considered prevention programs as effective for speed based on the systematic review of Hanlon et al. ${ }^{31}$ and the clinical effect observed. Nevertheless, it is necessary to interpret this result with caution due to the lack of reported confidence intervals.

Not all performance outcomes were collectively targeted in any one of the five systematic reviews included in this analysis. Strength was analyzed in four systematic reviews $^{29,31-33}$ covering 22 unique primary studies, which is the largest number of primary studies for any one of the outcomes studied. The parameters of balance, agility, jumping and speed were evaluated by fifteen, nine, ten and eleven unique primary studies, respectively. Furthermore, many of the primary studies were included in more than one review among the selected articles. This could have an influence on the results of this umbrella review.

This work provides a synthesis of the effects of lower extremity injury prevention programs on performance in sport populations. These elements allow the clinician to make more informed choices when implementing such strategies. While the results demonstrate the overall ef- 
fectiveness of prevention programs for sport performance, caution should be applied when interpreting the results because the efficacy of an intervention is defined in terms of its clinical significance and not only its statistical significance. The analyzed studies revealed vast heterogeneity among the populations that practiced a wide range of sports including soccer, floor hockey, futsal, volleyball or basketball. This may be due to selection bias, since we included studies covering a wide range of sporting populations of varying age, sex and playing level. The risk of publication bias also exists and while studies showing a statistically significant effect are more likely to be published, this aspect may play a role in the interpretation of the study results. A third important element is the study protocol variability; in fact, the length of implementation and frequency in practicing each of the different prevention programs was highly diverse. Consequently, performance bias may play a role in the analysis, but should be partially limited because the main outcomes of performance are objective measures. Furthermore, compliance was not comprehensively reported for all the included reviews and thus, could not be adequately presented within this umbrella review. Indeed, when studied, injury prevention program compliance is known to largely influence the outcome of the intervention (report bias). ${ }^{9,10}$ Additionally, current research suggests that adherence (proactive behavior) may be a more appropriate measure than compliance (passive behavior) when implementing exercise interventions. ${ }^{34,35}$ As noted by Brunner et al., 36 further studies should consider the systematic documentation of specific information such as the target population, details of performed drills with focus on intensity, frequency, type of exercise and duration, and a description of program implementation. Only through systematic documentation can data reproducibility be ensured for consistency when interpreting the reported results.

Further research should attempt to investigate some of the less studied outcomes such as agility or jumping, to bet- ter understand the potential improvements when practicing prevention programs. A second opportunity would be to study the effects of the different components (e.g. plyometrics and strength training) of the prevention programs separately. Understanding the individual effects of these components on performance and prevention would make it possible to (1) adapt these preventive programs to a specific sport context and (2) target certain determining aspects of sport performance in this context. The ultimate goal would be to encourage coaches to adhere to these programs as well as encourage athletes to regularly comply with them in an assiduous manner.

\section{CONCLUSION}

Injury prevention programs with multiple neuromuscular exercise components demonstrate overall efficacy to improve balance, agility, jumping and speed. For strength, the effects are varied, yet show a positive trend towards the usefulness of prevention programs. These beneficial effects on performance, coupled with demonstrated effectiveness in injury prevention, can be used as evidence for coaches to promote their implementation on a regular and consistent basis.

\section{CONFLICT OF INTEREST}

None of the authors have any conflicts of interest pertinent to this manuscript to disclose.

Submitted: June 24, 2021 CST, Accepted: September 21, 2021 CST 


\section{REFERENCES}

1. World Health Organisation. Global

Recommendations on Physical Activity for Health. WHO; 2010. Accessed March 30, 2020. https://www.w ho.int/dietphysicalactivity/global-PA-recs-2010.pdf

2. Soligard T, Steffen K, Palmer D, et al. Sports injury and illness incidence in the Rio de Janeiro 2016 Olympic Summer Games: A prospective study of 11274 athletes from 207 countries. Br J Sports Med. 2017;51(17):1265-1271. doi:10.1136/bjsports-2017-09 $\underline{7956}$

3. Clarsen B, Bahr R, Heymans MW, et al. The prevalence and impact of overuse injuries in five Norwegian sports: Application of a new surveillance method: The prevalence of overuse injury. Scand J Med Sci Sports. 2015;25(3):323-330. doi:10.1111/sm $\underline{\mathrm{s} .12223}$

4. Emery CA, Roy TO, Whittaker JL, Nettel-Aguirre A, van Mechelen W. Neuromuscular training injury prevention strategies in youth sport: a systematic review and meta-analysis. Br J Sports Med.

2015;49(13):865-870. doi:10.1136/bjsports-2015-0946 $\underline{39}$

5. Herman K, Barton C, Malliaras P, Morrissey D. The effectiveness of neuromuscular warm-up strategies, that require no additional equipment, for preventing lower limb injuries during sports participation: a systematic review. BMC Med. 2012;10(1):75. doi:10.11 $\underline{\text { 86/1741-7015-10-75 }}$

6. Hrysomallis C. Relationship between balance ability, training and sports injury risk. Sports Medicine. 2007;37(6):547-556. doi:10.2165/0000725 6-200737060-00007

7. Lauersen JB, Bertelsen DM, Andersen LB. The effectiveness of exercise interventions to prevent sports injuries: a systematic review and meta-analysis of randomised controlled trials. Br J Sports Med. 2014;48(11):871-877. doi:10.1136/bjsports-2013-0925 $\underline{38}$

8. Hübscher M, Zech A, Pfeifer K, Hänsel F, Vogt L, Banzer W. Neuromuscular training for sports injury prevention: a systematic review. Med Sci Sports Exerc. 2010;42(3):413-421. doi:10.1249/MSS.0b013e3181b88 $\underline{\mathrm{d} 37}$

9. Silvers-Granelli HJ, Bizzini M, Arundale A, Mandelbaum BR, Snyder-Mackler L. Higher compliance to a neuromuscular injury prevention program improves overall injury rate in male football players. Knee Surg Sports Traumatol Arthrosc. 2018;26(7):1975-1983. doi:10.1007/s00167-018-489 $\underline{5-5}$
10. Soligard T, Nilstad A, Steffen K, et al. Compliance with a comprehensive warm-up programme to prevent injuries in youth football. Br J Sports Med. 2010;44(11):787-793. doi:10.1136/bjsm.2009.070672

11. Steffen K, Emery CA, Romiti M, et al. High adherence to a neuromuscular injury prevention programme (FIFA 11+) improves functional balance and reduces injury risk in Canadian youth female football players: a cluster randomised trial. Br J Sports Med. 2013;47(12):794-802. doi:10.1136/bjsports-201 2-091886

12. Thorborg K, Krommes KK, Esteve E, Clausen MB, Bartels EM, Rathleff MS. Effect of specific exercisebased football injury prevention programmes on the overall injury rate in football: a systematic review and meta-analysis of the FIFA 11 and $11+$ programmes. $\mathrm{Br}$ J Sports Med. 2017;51(7):562-571. doi:10.1136/bjsport $\underline{\text { s-2016-097066 }}$

13. Bizzini M, Junge A, Dvorak J. Implementation of the FIFA $11+$ football warm up program: How to approach and convince the Football associations to invest in prevention. Br J Sports Med. 2013;47(12):803-806. doi:10.1136/bjsports-2012-0921 24

14. Myklebust G, Skjølberg A, Bahr R. ACL injury incidence in female handball 10 years after the Norwegian ACL prevention study: important lessons learned. Br J Sports Med. 2013;47(8):476-479. doi:10.1 136/bjsports-2012-091862

15. O'Brien J, Finch CF. The implementation of musculoskeletal injury-prevention exercise programmes in team ball sports: a systematic review employing the RE-AIM framework. Sports Med. 2014;44(9):1305-1318. doi:10.1007/s40279-014-020 8-4

16. White PE, Otago L, Saunders N, et al. Ensuring implementation success: how should coach injury prevention education be improved if we want coaches to deliver safety programmes during training sessions?: Table 1. Br J Sports Med. 2014;48(5):402-403. doi:10.1136/bjsports-2012-09198 $\underline{7}$

17. Donaldson A, Callaghan A, Bizzini M, Jowett A, Keyzer P, Nicholson M. A concept mapping approach to identifying the barriers to implementing an evidence-based sports injury prevention programme. Inj Prev. 2019;25(4):244-251. doi:10.1136/injurypre v-2017-042639 
18. Joy EA, Taylor JR, Novak MA, Chen M, Fink BP, Porucznik CA. Factors influencing the implementation of anterior cruciate ligament injury prevention strategies by girls soccer coaches. $J$ Strength Cond Res. 2013;27(8):2263-2269. doi:10.151 9/ISC.0b013e31827ef12e

19. Norcross MF, Johnson ST, Bovbjerg VE, Koester MC, Hoffman MA. Factors influencing high school coaches' adoption of injury prevention programs. J Sci Med Sport. 2016;19(4):299-304. doi:10.1016/i.jsams.2 $\underline{015.03 .009}$

20. Saunders N, Otago L, Romiti M, Donaldson A, White P, Finch C. Coaches' perspectives on implementing an evidence-informed injury prevention programme in junior community netball. Br J Sports Med. 2010;44(15):1128-1132. doi:10.1136/ bjsm.2009.069039

21. Twomey D, Finch C, Roediger E, Lloyd DG. Preventing lower limb injuries: Is the latest evidence being translated into the football field? J Sci Med Sport. 2009;12(4):452-456. doi:10.1016/j.jsams.2008.0 $\underline{4.002}$

22. Bolling C. "Who me? I thought you would never ask!” Applying qualitative methods in sports injury prevention research ( $\mathrm{PhD}$ Academy Award). $\mathrm{Br} J$ Sports Med. Published online August 21, 2020:bjsports-2020-102984. doi:10.1136/bjsports-202 0-102984

23. McGuigan M. Administration, scoring, and interpretation of selected tests. In: Essentials of Strength Training and Conditioning. 4th ed. National Strength and Conditioning Association; 2016.

24. Bolling C, Delfino Barboza S, van Mechelen W, Pasman HR. Letting the cat out of the bag: athletes, coaches and physiotherapists share their perspectives on injury prevention in elite sports. Br J Sports Med. 2020;54(14):871-877. doi:10.1136/bjsports-2019-1007 $\underline{73}$

25. Aromataris E, Fernandez R, Godfrey CM, Holly C, Khalil H, Tungpunkom P. Summarizing systematic reviews: methodological development, conduct and reporting of an umbrella review approach. Int J Evid Based Healthc. 2015;13(3):132-140. doi:10.1097/XE B.0000000000000055

26. Sharif MO, Sharif FNJ, Ali H, Ahmed F. Systematic reviews explained: AMSTAR-How to tell the good from the bad and the ugly. 2013;12(1):8.

27. Cohen J. Statistical Power Analysis for the Behavioural Science. 2nd ed. L. Erlbaum Associate; 1988.
28. Barengo N, Meneses-Echávez J, Ramírez-Vélez R, Cohen D, Tovar G, Bautista J. The impact of the FIFA $11+$ training program on injury prevention in football players: a systematic review. IJERPH. 2014;11(11):11986-12000. doi:10.3390/ijerph1111119 $\underline{86}$

29. Faude O, Rössler R, Petushek EJ, Roth R, Zahner L, Donath L. Neuromuscular adaptations to multimodal injury prevention programs in youth sports: a systematic review with meta-analysis of randomized controlled trials. Front Physiol. 2017;8:791. doi:10.338 9/fphys.2017.00791

30. Gomes Neto M, Conceição CS, de Lima Brasileiro AJA, de Sousa CS, Carvalho VO, de Jesus FLA. Effects of the FIFA 11 training program on injury prevention and performance in football players: a systematic review and meta-analysis. Clin Rehabil. 2017;31(5):651-659. doi:10.1177/0269215516675906

31. Hanlon C, Krzak JJ, Prodoehl J, Hall KD. Effect of injury prevention programs on lower extremity performance in youth athletes: a systematic review. Sports Health. 2020;12(1):12-22. doi:10.1177/1941738 119861117

32. Monajati A, Larumbe-Zabala E, Goss-Sampson M, Naclerio F. The effectiveness of injury prevention programs to modify risk factors for non-contact anterior cruciate ligament and hamstring injuries in uninjured team sports athletes: a systematic review. Cavarretta E, ed. PLoS ONE. 2016;11(5):e0155272. do $\mathrm{i}: 10.1371 /$ journal.pone.0155272

33. ter Stege MHP, Dallinga JM, Benjaminse A, Lemmink KAPM. Effect of interventions on potential, modifiable risk factors for knee injury in team ball sports: a systematic review. Sports Med. 2014;44(10):1403-1426. doi:10.1007/s40279-014-021 $\underline{6-4}$

34. Owoeye OBA, Emery CA, Befus K, PalaciosDerflingher L, Pasanen K. How much, how often, how well? Adherence to a neuromuscular training warmup injury prevention program in youth basketball. $J$ Sport Sci. 2020;38(20):2329-2337. doi:10.1080/026404 $\underline{14.2020 .1782578}$

35. Owoeye OBA, McKay CD, Verhagen EALM, Emery CA. Advancing adherence research in sport injury prevention. Br J Sports Med. 2018;52(17):1078-1079. d oi:10.1136/bjsports-2017-098272

36. Brunner R, Friesenbichler B, Casartelli NC, Bizzini M, Maffiuletti NA, Niedermann K. Effectiveness of multicomponent lower extremity injury prevention programmes in team-sport athletes: an umbrella review. Br J Sports Med. 2019;53(5):282-288. doi:10.11 36/bjsports-2017-098944 


\section{SUPPLEMENTARY MATERIALS}

\section{Appendix 1}

Download: https://ijspt.scholasticahq.com/article/29860-lower-limb-exercise-based-injury-prevention-programs-areeffective-in-improving-sprint-speed-jumping-agility-and-balance-an-umbrella-review/attachment/75404.docx

\section{Appendix 2}

Download: https://ijspt.scholasticahq.com/article/29860-lower-limb-exercise-based-injury-prevention-programs-areeffective-in-improving-sprint-speed-jumping-agility-and-balance-an-umbrella-review/attachment/76021.docx 